CRYOBIOLOGY 33, 465-471 (1996)

ARTICLE NO. 0047

\title{
Culture of Graft-Infiltrating Cells from Cryopreserved Endomyocardial Biopsies
}

\author{
G. A. PATIJN, $* \dagger$ L. M. B. VAESSEN, $\dagger$ W. WEIMAR, $\dagger$ \\ F. H. J. CLAAS, ${ }^{*}$ AND N. H. P. M. JUTTE $\dagger$ \\ *Department of Immunohaematology and Blood Bank, University Hospital, Leiden, The Netherlands; \\ and $\dagger$ Department of Internal Medicine I, Erasmus University Rotterdam/University Hospital Rotterdam- \\ Dijkzigt, Rotterdam, The Netherlands
}

\begin{abstract}
Graft-infiltrating cells can be cultured from fresh endomyocardial biopsies (EMB) taken after heart transplantation to determine their growth patterns, phenotypic composition, and functional characteristics for clinical or scientific purposes. In this study we investigated whether graft-infiltrating cells can also be cultured successfully after cryopreservation of these EMB. Three different cryopreservation methods were used. One method gave successful growth in $100 \%$ of the cases $(n=6)$ : The biopsy fragments were preincubated in $10 \% \mathrm{vol} / \mathrm{vol}$ dimethyl sulfoxide during $5 \mathrm{~min}$ at $0^{\circ} \mathrm{C}$, frozen to $-70^{\circ} \mathrm{C}$ at approximately $1^{\circ} \mathrm{C}$ per minute, and subsequently immersed and stored in liquid nitrogen. Thawing was performed rapidly in water at $37^{\circ} \mathrm{C}$. In addition, the effect of cryopreservation on cell surface phenotype and donor-specific cytotoxicity of these graft-infiltrating cells was analyzed. When compared to cultures of nonfrozen control biopsies, both qualities remained constant in most cases, although a variation in $\mathrm{CD} 4^{+} / \mathrm{CD}^{+}$cell ratio was observed in $33 \%$ of these cultures. However, when nonfrozen fragments of size-matched biopsies were cultured separately, a similar variation in phenotype was noted, indicating that this phenomenon can be attributed to sampling variation and not to the cryopreservation procedure. The present findings suggest that it is no longer required to culture fresh (nonfrozen) post-transplant EMB to propagate graft-infiltrating cells: Culturing can be limited to cryopreserved EMB that are selected retrospectively, depending on actual clinical or scientific interests. Besides greatly facilitating the long-term monitoring of heart transplant recipients, this also means a substantial decrease in cost and work load for laboratories involved in heart transplantation. (ㅇ 1996 Academic Press, Inc.
\end{abstract}

Endomyocardial biopsies (EMB) are taken at regular intervals after heart transplantation in order to assess the clinical diagnosis of graft rejection on a histological basis. In addition, graft-infiltrating cells can be cultured from such EMB and their growth patterns, phenotypic composition, and functional characteristics can be determined for clinical or scientific purposes $(4,12)$.

Since routine culturing of every EMB taken for this purpose is very costly and timeconsuming, the question was raised whether biopsies could be cryopreserved without damaging the growth potential of the graftinfiltrating cells. If so, all EMB could be cryopreserved on a routine basis and only

Received January 9, 1996; accepted June 3, 1996. selected samples could be thawed and cultured retrospectively depending on actual clinical and scientific interests.

Cryopreservation of EMB for this purpose has so far not been reported. Therefore, we investigated in the present study whether in vivo-activated graft-infiltrating cells can be cultured from cryopreserved post-transplant EMB using three cryopreservation methods. The conditions that are generally considered optimal for cryopreservation of human lymphocytes $(3,6,7,8,11)$ were applied in all three methods. In the experimental groups we examined the effect of the preincubation (equilibration) of the EMB in cryopreservation medium prior to freezing, and the effect of culturing the biopsy for a brief period before freezing, since these variables have been reported to improve the functional survival of 
tissue fragments such as pancreatic islets $(1,9,10,13,14,16)$. In addition, phenotypic characteristics and cytotoxic activity of lymphocyte cultures propagated from cryopreserved biopsies were compared to those of cultures from nonfrozen controls.

\section{MATERIALS AND METHODS}

A total of 20 fresh EMB was obtained from seven different heart transplant recipients by right ventricular catheterization. The biopsies were taken at different time points, but no later than 5 months after transplantation.

Biopsies with approximate size of $2-3 \mathrm{~mm}^{3}$ were used for the experiments. Each fresh biopsy was split into two equal parts. The first half of each biopsy was divided into three smaller fragments to facilitate growth of graftinfiltrating cells. Subsequently these fragments were cultured separately. The second half of each biopsy was frozen after being allocated randomly to one of three different cryopreservation protocols. After thawing, each sample was divided into three fragments that were cultured separately.

\section{Culture}

Each of the three fragments of the fresh and the cryopreserved biopsy was placed in one well of a 96-well round-bottom tissue culture plate (Costar 3799, Cambridge, MA) with 200 $\mu \mathrm{l}$ culture medium and $10^{5}$ irradiated (40 Gy) autologous peripheral blood mononuclear cells (PBMC, isolated by Ficoll-Isopaque $(\delta=1.077)$ density-gradient centrifugation $)$ as feeder cells.

EMB were cultured in RPMI 1640 Dutch modification (Gibco, Paisley, Scotland) supplemented with $10 \% \mathrm{vol} / \mathrm{vol}$ lectin-free Lymphocult-T-LF (Biotest GmbH, Dreieich, Germany) as exogenous source of interleukin 2, $10 \%$ pooled human serum, $4 \mathrm{~m} M$ L-glutamine, $100 \mathrm{IU} / \mathrm{ml}$ penicillin, and $100 \mu \mathrm{g} / \mathrm{ml}$ streptomycin at $37^{\circ} \mathrm{C}$ in a humidified $\mathrm{CO}_{2}$ incubator. Half the culture medium was replaced by fresh medium every 2 to 3 days.

Cells propagated from the three fragments were pooled before further analysis was performed. Cell growth of graft-infiltrating cells was considered positive when the yield was $10^{6}$ cells or more, i.e., the minimal number required to perform the phenotypic analysis.

\section{Cryopreservation and Thawing}

The second half of each biopsy sample was frozen according to one of three different cryopreservation protocols.

Method I. The sample was transferred into a cryotube with $1 \mathrm{ml}$ RPMI 1640 Dutch modification containing $10 \% \mathrm{vol} / \mathrm{vol}$ pooled human serum and $10 \%$ vol/vol (1.41 $M$ ) dimethyl sulfoxide at $0^{\circ} \mathrm{C}$ and subsequently frozen in a glasswool-insulated polystyrene container to $-70^{\circ} \mathrm{C}$ at an average of $1^{\circ} \mathrm{C} / \mathrm{min}$ (determined by direct continuous measurement of sample temperature; data not shown), immediately followed by immersion and storage of sample tubes in liquid nitrogen $\left(-196^{\circ} \mathrm{C}\right)$ for a minimum of 3 weeks. The sample was thawed rapidly (in approximately $1 \mathrm{~min}$ ) by shaking the tube in a water bath of $37^{\circ} \mathrm{C}$. Directly after thawing the sample was placed in RPMI 1640 containing $10 \mu \mathrm{g} / \mathrm{ml}$ DNAase and 50\% human serum, and subsequently washed twice in RPMI 1640 with $10 \%$ human serum. The sample was then divided into three fragments that were subsequently cultured.

Method II. Freezing and thawing were as in method I. However, immediately before freezing the sample was exposed to the cryopreservation medium during $5 \mathrm{~min}$ at $0^{\circ} \mathrm{C}$ in melting ice, instead of transferring the tube immediately into the $-70^{\circ} \mathrm{C}$ freezer.

Method III. The fresh sample was incubated (cultured) during $24 \mathrm{~h}$ in culture medium, followed by the protocol applied in Method II.

\section{Phenotypic Analysis}

Surface differentiation antigens of the cultured graft-infiltrating cells were analyzed by twocolor flow cytometry after staining with monoclonal antibodies directed against CD3 (antileu4) as a pan T-cell marker, the $\alpha / \beta$ chain of the T-cell receptor (WT31), and CD4 (anti-leu3) 
and CD8 (anti-leu2) as T-cell subset markers. Antibodies were conjugated directly to fluorescein (FITC) or phycoerythrin (PE) (BectonDickinson, Mountain View, CA).

Cells were double-stained with two antibodies conjugated to different fluorochromes; $10^{5}$ cells were incubated for $30 \mathrm{~min}$ at $4^{\circ} \mathrm{C}$ in $50 \mu \mathrm{l}$ Hanks balanced salt solution (Biochrom $\mathrm{KG}$, Berlin) with antibodies containing $1 \%$ bovine serum albumin and $0.1 \%$ sodiumazide. After washing, cell surface differentiation antigens were analyzed with a fluorescence-activated cell scan flow-cytometer (Becton-Dickinson).

\section{Cell-Mediated Lympholysis (CML)}

In a standard 4-h ${ }^{51} \mathrm{Cr}$-release assay, cytotoxicity was tested against donor cells and against the K562 cell line for assessment of natural killer (NK) and lymphokine-activated killer (LAK) cell reactivity. Target cells were incubated for $1.5 \mathrm{~h}$ at $37^{\circ} \mathrm{C}$ in the presence of $200 \mu \mathrm{Ci}{ }^{51} \mathrm{Cr}\left(\mathrm{Na}_{2} \mathrm{CrO}_{4} 5 \mathrm{mCi} / \mathrm{ml}\right.$, sp act $350-$ $600 \mathrm{mCi} / \mathrm{mg}$ chromium; Amersham, UK) and subsequently washed. ${ }^{51} \mathrm{Cr}$-labeled target cells $\left(2.5 \times 10^{3}\right)$ were mixed with effector cells in effector-target ratios from 40:1 to $1.25: 1$ in round-bottom tissue culture plates with $0.2 \mathrm{ml}$ RPMI containing $10 \%$ human serum per well. The plates were centrifuged at $600 \mathrm{~g}$ for $1 \mathrm{~min}$ and incubated at $37^{\circ} \mathrm{C}$, and supernatants were collected after $4 \mathrm{~h}$ (Skatron AS, Lier, Norway). Spontaneous chromium release was determined by incubation of targets in $0.2 \mathrm{ml}$ culture medium, and maximum release was obtained by adding $10 \%$ Triton X-100 detergent ( $5 \% \mathrm{vol} / \mathrm{vol}$ solution in 0.01 TRIS buffer) to the targets. Experimental, spontaneous, and maximal release were assessed in quadruplicate. Specific lysis was calculated with the following equation:

Specific lysis $=100 \%$

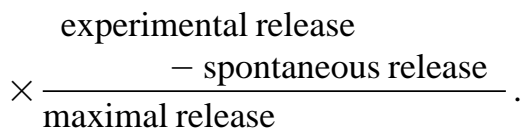

- spontaneous release

\section{TABLE 1}

Number of Cultures Showing Growth of Graft-Infiltrating Cells from Cryopreserved Post-transplant EMB Compared to the Number of Growing Cultures from the Nonfrozen Parts of These EMB, Using Three Different Cryopreservation Methods

\begin{tabular}{ccc}
\hline & \multicolumn{2}{c}{$\begin{array}{c}\text { Number of growing cultures } \\
\text { from EMB }\end{array}$} \\
\cline { 2 - 3 } $\begin{array}{c}\text { Cryopreservation } \\
\text { method }\end{array}$ & Nonfrozen & Frozen-thawed \\
\cline { 2 - 3 } I & 4 & $1(25 \%)$ \\
II & 6 & $6(100 \%)$ \\
III & 5 & $2(40 \%)$ \\
\hline
\end{tabular}

Spontaneous release was generally $10-15 \%$ of maximal release. An assay was considered positive when the percentage of specific lysis of donor antigen-bearing target cells exceeded $10 \%$. A series of double-dilution studies revealed that lysis percentages of less than $10 \%$ are within the variation range of the assay (12).

\section{RESULTS}

\section{Generation of Graft-Infiltrating Cell \\ Cultures}

Cell growth from nonfrozen (fresh) biopsies was obtained in 15 out of 20 cases. None of the frozen counterparts of the five "non-growing' biopsies did show cell growth. The counterparts of the 15 " growing" nonfrozen biopsies had been cryopreserved as follows: 4 according to Method I, 6 according to Method II, and 5 according to Method III. When these cryopreserved parts were thawed and cultured, 1 out of 4 biopsies frozen by Method I yielded cell growth $(25 \%), 6$ out of 6 biopsies frozen by Method II resulted in cell growth (100\%), and 2 out of 5 biopsies frozen by Method III yielded cell growth (40\%) (Table 1). Thus Methods I, II, and III together yielded a total of 9 biopsies with cell growth from both the nonfrozen and cryopreserved fragment.

The average time of culture per EMB, before the analysis of phenotype and cytotoxicity was performed, was similar for the nonfro- 
zen and the cryopreserved fragments: 6 weeks (4-8), and 7 weeks (5-8), respectively.

\section{Phenotypic Analysis}

All nine pairs of cultures propagated from the nonfrozen biopsy and its cryopreserved counterpart were analyzed by flow cytometry. When comparing the cultures of the nonfrozen and cryopreserved parts, no differences in phenotype were observed in six out of these nine pairs of cultures. However, in three cases $(33 \%)$ the predominance of $\mathrm{CD}^{+}$or $\mathrm{CD}^{+}$cells had shifted after cryopreservation, although this occurred in either direction: Either mainly $\mathrm{CD}^{+}{ }^{+}$cells were found in the nonfrozen culture and $\mathrm{CD}^{+}$cells in the frozen-thawed culture, or the reverse was found (Table 2).

To test whether these phenotypic differences were generated by the cryopreservation procedure or by sampling variation, we divided 10 size-matched fresh (nonfrozen) biopsies into four fragments each, which were all cultured separately. For comparison with the previous experiments, the separate cultures from two fragments were pooled, yielding two cell populations from one single biopsy. Subsequently, phenotypic analysis was performed. In 7 out of 10 biopsies the cultures showed $>5 \%$ differences in phenotype of one $\mathrm{T}$-cell subset between the homologous counterparts, indicating that the differences after cryopreservation can be attributed to sample variation (Table 3) and occurred with equal frequency as in homologous frozen/nonfrozen EMB counterparts (Fisher's exact test).

\section{Cell-Mediated Cytotoxicity}

A cell number sufficient to perform a CML assay could be propagated in four out of the nine pairs of cultures that had been analyzed by flow cytometry. In three out of these four tested pairs of cultures, donor-specific cytotoxicity was positive in the culture from both the nonfrozen and the cryopreserved sample. In the remaining pair no donor-specific lysis was found in either the nonfrozen or the cryopreserved culture. In one biopsy, K562 lysis

\section{TABLE 2}

Cell Surface Phenotype of Graft-Infiltrating Cell Cultures Propagated from Nine Fragments of Cryopreserved EMB, Compared to the Cultures Propagated from the Nonfrozen Counterparts (Controls)

\begin{tabular}{|c|c|c|}
\hline \multirow[b]{2}{*}{ Phenotype } & \multicolumn{2}{|c|}{ Percentage of cells in culture } \\
\hline & $\begin{array}{c}\text { Nonfrozen } \\
(\%)\end{array}$ & $\begin{array}{c}\text { Frozen-thawed } \\
\qquad(\%)\end{array}$ \\
\hline CD4 & 91 & 99 \\
\hline CD8 & 0 & 0 \\
\hline WT31 neg & 0 & 0 \\
\hline CD4 & $2 *$ & $93^{*}$ \\
\hline CD8 & $18^{*}$ & $4 *$ \\
\hline WT31 neg & 80 & 0 \\
\hline CD4 & 99 & 98 \\
\hline CD8 & 0 & 0 \\
\hline WT31 neg & 0 & 0 \\
\hline CD4 & $95^{*}$ & $3 *$ \\
\hline CD8 & $5^{*}$ & $91 *$ \\
\hline WT31 neg & 0 & 0 \\
\hline CD4 & $35^{*}$ & $98 *$ \\
\hline CD8 & $64 *$ & $0 *$ \\
\hline WT31 neg & 0 & 0 \\
\hline CD4 & 2 & 0 \\
\hline CD8 & 98 & 100 \\
\hline WT31 neg & 0 & 0 \\
\hline CD4 & 97 & 95 \\
\hline CD8 & 1 & 2 \\
\hline WT31 neg & 0 & 0 \\
\hline CD4 & 4 & 3 \\
\hline CD8 & 95 & 96 \\
\hline WT31 neg & 0 & 0 \\
\hline CD4 & 92 & 100 \\
\hline CD8 & 5 & 0 \\
\hline WT31 neg & 0 & 0 \\
\hline
\end{tabular}

Note. WT31-negative cells consisted of either natural killer cells of $\gamma / \delta$ receptor-positive T-cells. In six out of nine tested pairs of cultures $(66 \%)$ no differences in phenotype were observed after cryopreservation. In three cases $(33 \%)$ the $\mathrm{CD}^{+} / \mathrm{CD}^{+}$cell ratio had changed (marked with *).

was apparent in the cells from the nonfrozen biopsy, but not in the culture propagated from its cryopreserved counterpart. However, also in this case the donor-specific reactivity remained constant in both cultures. Thus donorspecific cytotoxicity is comparable before and after cryopreservation in this study $(n=4)$ (Table 4). 
TABLE 3

Cell Surface Phenotype of Graft-Infiltrating Cell

Cultures from 10 Nonfrozen Post-transplant EMB

\begin{tabular}{|c|c|c|}
\hline \multirow[b]{2}{*}{ Phenotype } & \multicolumn{2}{|c|}{$\begin{array}{l}\text { Percentage of cells } \\
\text { per culture }\end{array}$} \\
\hline & $\begin{array}{l}\text { Part I } \\
(\%)\end{array}$ & $\begin{array}{c}\text { Part II } \\
(\%)\end{array}$ \\
\hline CD4 & $88 *$ & $98^{*}$ \\
\hline CD8 & 11 & 1 \\
\hline WT31 neg & 0 & 0 \\
\hline CD4 & 97 & 97 \\
\hline CD8 & 3 & 2 \\
\hline WT31 neg & 0 & 0 \\
\hline CD4 & $59 *$ & $18^{*}$ \\
\hline CD8 & $30 *$ & $68^{*}$ \\
\hline WT31 neg & 9 & 12 \\
\hline CD4 & $16^{*}$ & $7 *$ \\
\hline CD8 & $51 *$ & $20 *$ \\
\hline WT31 neg & 30 & 73 \\
\hline CD4 & $34 *$ & $1 *$ \\
\hline CD8 & $54 *$ & $6^{*}$ \\
\hline WT31 neg & 11 & 91 \\
\hline CD4 & $99 *$ & $20 *$ \\
\hline CD8 & $0^{*}$ & $49^{*}$ \\
\hline WT31 neg & 0 & 30 \\
\hline $\mathrm{CD} 4$ & $68 *$ & $82 *$ \\
\hline CD8 & 10 & 15 \\
\hline WT31 neg & 21 & 0 \\
\hline CD4 & $70 *$ & $87^{*}$ \\
\hline CD8 & 12 & 10 \\
\hline WT31 neg & 15 & 0 \\
\hline CD4 & 100 & 100 \\
\hline CD8 & 0 & 0 \\
\hline WT31 neg & 0 & 0 \\
\hline CD4 & 57 & 62 \\
\hline CD8 & 30 & 25 \\
\hline WT31 neg & 0 & 13 \\
\hline
\end{tabular}

Note. Each EMB was divided in fragments, which were cultured and analyzed separately. WT31-negative cells consisted of either natural killer cells or $\gamma / \delta$ receptorpositive T-cells. In 3 out of 10 tested pairs of cultures (30\%) the CD4/CD8 compositions were identical. In 7 cases $(70 \%)$ the phenotype had change (marked with *).

\section{DISCUSSION}

The present results show that in vivo-activated graft-infiltrating cells can be cultured from cryopreserved endomyocardial biopsies taken after heart transplantation. One cryo- preservation protocol was successful in $100 \%$ of the cases.

Each tissue from each species requires specific cryopreservation conditions for optimal functional survival and preservation of cell structure and characteristics (10). For lymphocytes, important variables in this respect include the kind and concentration of cryoprotective agent, the extent of permeation of the cryoprotectant before freezing, the presence and concentration of serum in the cryopreservation medium, the freezing and the thawing rate, and the conditions of dilution after thawing (17).

For human lymphocytes the optimal cryopreservation conditions are well established $(3,6,7,8,11)$ and these were applied in this study in all experimental groups. For EMB a cryopreservation protocol has not yet been reported. To establish such a protocol for EMB in order to culture graft-infiltrating cells, we investigated the effect of variables that have been shown to improve the functional survival of tissue fragments (i.e., pancreatic islets) rather than cell suspensions. One factor that has been reported to improve the functional survival of pancreatic islets is the preincubation of the tissue sample in the cryoprotective agent before freezing (equilibration) $(1,10,13,16)$. This procedure allows deep permeation of dimethyl sulfoxide into the intracellular compartments and is therefore

TABLE 4

Donor-Specific Cytotoxicity of Graft Infiltrating Cell Cultures from Cryopreserved Posttransplant EMB, Compared to the Cultures of the Nonfrozen Counterparts of these EMB

\begin{tabular}{lcc}
\hline & \multicolumn{2}{c}{ Specific lyele } \\
\cline { 2 - 3 } & $\begin{array}{c}\text { Nonfrozen } \\
(\%)\end{array}$ & $\begin{array}{c}\text { Frozen-thawed } \\
(\%)\end{array}$ \\
\hline Biopsy & 29 & 20 \\
EMB 1 & 10 & 11 \\
EMB 2 & 49 & 39 \\
EMB 3 & 0 & 5 \\
EMB 4 & & \\
\hline
\end{tabular}


more effective in protecting the cells against slow freezing injury. The exposure of the sample to the agent should take place at $0^{\circ} \mathrm{C}$ to prevent toxic damage (13). In the present study we followed the method published by Bank et al. (1), which involved a relatively brief period of exposure $(5 \mathrm{~min}$ ) of the EMB to $10 \% \mathrm{vol} / \mathrm{vol}$ dimethyl sulfoxide at $0^{\circ} \mathrm{C}$ prior to the initiation of freezing, which Taylor et al. referred to as the "partial" equilibration protocol (16). Also, for freezing islets of Langerhans such partial equilibration was successful in combination with slow cooling $\left(<10^{\circ} \mathrm{C}\right)$ and fast warming (16), as comparable to the protocol used presently.

This method appeared to be the most successful of the three protocols tested in the present study: graft-infiltrating cell growth in cultures of cryopreserved EMBs was observed in $100 \%$ of the cases (Method II). Freezing without preincubation of the sample in dimethyl sulfoxide yielded cell growth in only $25 \%$ of the cases (Method I). This suggests that preincubation of the biopsy in the cryoprotective agent increases permeation of the cryoprotectant into the tissue sufficiently to improve cryopreservation of graft infiltrating cells inside EMB.

Another factor that has been reported to be beneficial to the functional survival of pancreatic islets is prefreezing a culture of tissue samples for $1-2$ days $(9,14)$. In the present study culture of EMBs for $24 \mathrm{~h}$ directly before freezing resulted in cell growth in no more than $40 \%$ of the cases (Method III). This procedure therefore did not significantly improve the yield of graft-infiltrating cells from cryopreserved EMBs.

When compared to nonfrozen controls, the cell surface phenotype of graft-infiltrating cells propagated from cryopreserved EMBs remained constant in most cases, although a variation in the $\mathrm{CD} 4^{+} / \mathrm{CD}^{+}$cell ratio was observed in $33 \%$ of the tested cultures. An additional experiment comparing the phenotypes of cultures propagated from two nonfrozen fragments of size-matched biopsies $(n=10)$ showed at least a similar variation $(70 \%)$, indicating that the observed differences between nonfrozen and cryopreserved cultures can be attributed to sampling variation and not to the cryopreservation procedure.

Besides sampling variation, dominance of a particular cell subpopulation as a result of growth rate differences may also cause variation in phenotype. However, this phenomenon is most likely not a significant causal factor with respect to the observed variation in phenotype in this study, since the average time of culture of the nonfrozen and the cryopreserved fragments was comparable.

A substantial literature indicates that the ability of cryopreserved lymphocytes to undergo blastogenesis in response to antigenic mitogenic, and allogeneic stimuli is unimpaired $(2,3,6,11,15)$. In contrast, the ability of cryopreserved lymphocytes to perform as cytotoxic effector cells as effectively as their fresh counterparts is controversial. In accordance with the observations of Dubois et al. (3), Friedman et al. (5) and Yamada et al. (8), but contrary to those reported by others (2, 11), we have demonstrated in the present study that the specific cytotoxicity of graftinfiltrating cells against donor cells is not compromised by cryopreservation when measured in a standard chromium release assay.

In conclusion, this study shows for the first time that graft-infiltrating cells can be cultured from cryopreserved EMB taken after heart transplantation. We established a cryopreservation protocol that was successful in $100 \%$ of the cases. The phenotype and donor-specific cytotoxicity of cultures propagated from cryopreserved EMB were comparable to the nonfrozen controls. Although the total number of cases tested in this study was relatively small, these promising results encourage further experiments using this protocol. The present findings suggest that culturing of selected cryopreserved biopsies can be performed retrospectively depending on actual clinical or scientific interests. Besides greatly facilitating the long-term monitoring of heart transplant 
recipients, it could also mean a substantial decrease in cost and work load for laboratories that are currently culturing fresh EMB for these purposes.

\section{ACKNOWLEDGMENTS}

We thank C. C. Baan, N. M. van Besouw, and C. R. Daane for excellent technical assistance.

\section{REFERENCES}

1. Bank, H. L., Davis, R. F., and Emerson, D. Cryogenic preservation of isolated rat islets of Langerhans: Effect of cooling and warming rates. Diabetologia 16, 195-199 (1979).

2. Callery, C. D., Golightly, M., Sidell, N., and Golub, S. H. Lymphocyte surface markers and cytotoxicity following cryopreservation. J. Immunol. Methods 35, 213-223 (1980).

3. Du Bois, M. J., Schellekens, P. T., De Wit, J. J., and Eijsvoogel, V. P. In vitro reactivity of human lymphocytes after cryopreservation using a programmed cooling device. Scand. J. Immunol. 5(Suppl. 5), 17-22 (1976).

4. Duquesnoy, R. J., Trager, J. D., and Zeevi, A. Propagation and characterization of lymphocytes from transplant biopsies. Crit. Rev. Immunol. 10, 455480 (1991).

5. Friedman, S. M., Hunter, S. B., Thomas, Y., and Chess, L. Hapten-specific human T cell lines. I Functional analysis with respect to cytotoxic and helper activity. J. Immunol. 125, 2202 (1980).

6. Golub, S. H., Sulit, H. L., and Morton, D. L. The use of viable frozen lymphocytes for studies in human tumor immunology. Transplantation 19, 195-202 (1975).

7. Holden, H. T., Oldham, R. K., Ortaldo, J. R., and Heberman, R. B. In "In Vitro Methods in CellMediated and Tumor Immunity"' (B. Bloom and J. R. David, Eds.), pp. 723-729. Academic Press, New York, 1976.

8. Ichino, Y., and Ishikawa, T. Effects of cryopreservation on human lymphocyte functions: Comparison of programmed freezing method by a direct control system with a mechanical freezing method. J. Immunol. Methods 77, 291-295 (1985).
9. Ishihara, K., Taniguchi, H., et al. Evaluation of cryopreservation techniques of pancreatic fragments and islets in vitro and in vivo. Diab. Res. Clin. Prac. 5, 285-293 (1988).

10. Mazur, P. Stopping biological time: The freezing of living cells. Ann. N.Y. Acad. Sci. 541, 514-531 (1988).

11. Oldham, R. K., Dean, J. H., Cannon, G. B., Ortaldo, J. R., Dunston, G., Applebaum, F., McCoy, J. L., Djeu, J., and Herberman, R. B. Cryopreservation of human lymphocyte function as measured by in vitro assays. Int. J. Cancer 18, 145 (1976).

12. Ouwehand, A. J., Vaessen, L. M. B., Baan, C. C., Jutte, N. H. P. M., Balk, A. H. M. M., Essed, C. E., Bos, E., Claas, F. H. J., and Weimar, W. Alloreactive lymphoid infiltrates in human heart transplants. Hum. Immunol. 30, 50-59 (1991).

13. Rajotte, R. V., and Mazur, P. Survival of frozenthawed fetal rat pancreases as a function of the permeation of dimethyl-sulfoxide and glycerol, warming rate, and fetal age. Cryobiology 18, 1731 (1981).

14. Sandler, S., and Andersson, A. The significance of culture for successful cryopreservation of isolated pancreatic islets of Langerhans. Cryobiology 21, 503-510 (1984).

15. Strong, D. M., Woody, J. N., Factor, M. A., Ahmed, A., and Sell, K. W. Immunologic responsiveness of frozen-thawed human lymphocytes. Clin. Exp. Immunol. 21, 442-455 (1975).

16. Taylor, M. J., and Benton, M. J. Interaction of cooling rate, warming rate, and extent of permeation of cryoprotectant in determining survival of isolated rat islets of Langerhans during cryopreservation. Diabetes 36, 59-65 (1987).

17. Thorpe, P. E., Knight, S. C., and Farrant, J. Optimal conditions for the preservation of mouse lymph node cells in liquid nitrogen using cooling rate techniques. Cryobiology 13, 126-133 (1976).

18. Yamada, H., Kodera, Y., and Yamada, K. Cryopreservation of human peripheral blood lymphoid cells reactive to allogeneic antigens, virus-transformed autologous cells and autologous leukemia cells in in vitro sensitization. Nagoya J. Med. Sci. 44, 177 (1982). 